\title{
Road and Bridge Infrastructure Development Issues in Benin Republic: Analysis and Perspectives
}

\author{
Dossa Didier Boko-haya*, Yadong Li, Changrong Yao, Saizhi Liu, Qiqi Xiang \\ Department of Bridge Engineering, Southwest Jiaotong University, Chengdu, China

\section{Email address:} \\ boko-haya.dd@home.swjtu.edu.cn (D. D. Boko-haya),ydli@swjtu.cn (Yadong Li),68049721@qq.com (Changrong Yao), \\ liusaizhi@126.com (Saizhi Liu),214320104@qq.com (Qiqi Xiang) \\ ${ }^{*}$ Corresponding author
}

\section{To cite this article:}

Dossa Didier Boko-haya, Yadong Li, Changrong Yao, Saizhi Liu, Qiqi Xiang. Road and Bridge Infrastructure Development Issues in Benin Republic: Analysis and Perspectives. American Journal of Civil Engineering. Vol. 5, No. 1, 2017, pp. 9-15.doi: 10.11648/j.ajce.20170501.12

Received: November 4, 2016; Accepted: November 14, 2016; Published: December 2, 2016

\begin{abstract}
Roads and Bridges (R-B) infrastructure development in Benin Republic have being topical issues and have been identified by many as crucial components for economic development of the country. In light of the above, this study analyzes the R-B infrastructure agreeable priority issues, by diagnosing the current problems of development and the perspectives. Historical as well as descriptive approaches were adopted in data collection and were complemented by surveys. The study revealed, on one hand, the large gap between national R-B provision and the road transportation demand, and in the other hand, an inequality in the provision of road infrastructure and rehabilitation of roads in the area, resulting in disparities in the level of development. Based on this, the paper concludes with a range of best recommendations and proposals formulated in aim to respond efficiently to the R-B problems in Benin Republic and meet today's development goals.
\end{abstract}

Keywords: Roads, Bridges, Socio-Economic Development, Analysis and Perspectives, Benin Republic

\section{Introduction}

Road networks and bridges system play an important role in the connection of different regions. It also facilitates trade and cooperation between countries areas of the globe. As urbanization gathered pace in many regions, the problems of inadequacy in R-B infrastructure system and deterioration on environment became enormous. The pressure on these systems, however, in terms of rapid population growth, spatial expansion and R-B infrastructure development needs is often high.

In Benin Republic, the issue of R-B development has continued to be of national importance [1]. For instance, most of the national R-B infrastructures are in poor condition [1-4], and this has imposed significant cost on the national economy especially to the agricultural activities due to increased vehicle operating costs and travel times (World Bank, 2015). Attempt to continually provide efficient and effective transport system on various programs to ensure the provision of adequate bridges and roads transport facilities to meet the needs of the Beninese, has been recognized by the
National Government of Benin (NGB) over the years. Examples of such attempt were Growth and Poverty Reduction Strategy (GPRS), the Strategic Development Orientations (SDOs), the Transport Sector Strategy (TSS), Priority Action Program (PAP), the National Directorate of Road Maintenance and Feeder Roads (DNERPR); the Directorate of Roads and Constructive Works (DROA); the Directorate for Major Road Projects (DGPR) and SubDirectorate of Programming and Monitoring-Evaluation at the National Directorate of Road and Feeder Roads Maintenance (DNERPR), [5-7]. However, the pace of progress in R-B development varies from one region to another and is insufficient to reach the 2025 Agenda targets for sustainable development [8].

The contention of the policy makers is that national infrastructure assets, especially R-B if adequately provided, can enhance the quality of Beninese life [9-11]. Further, the importance of national transport facilities can be justified from both social and economic perspectives. Socially, a significant proportion of Benin population lives in both urban and rural areas and demands various forms of transport to facilitate sociopolitical interactions. Economically, rural areas are indispensable 
in the supply of food, raw materials and finished products to urban centers and the Benin's economic growth as a whole.

Ensuring R-B infrastructure progress for Beninese, rapidly expanding and increasingly mobile populations remains a considerable challenge in the whole country area.

In light of the above, it becomes expedient to examine R-B infrastructure agreeable priority issues within Benin, so that the extent of the problems can be know and possible solution proffered to achieving sustainable national development. The study used historical as well as descriptive approaches in data collection and were complemented by surveys designed to gather all necessary information in an effective way to understand a given research problem from the perspectives of the different regions areas. It is our hope that this research work will continue to inform decisions and to stimulate a rich dialogue on the way forward for Benin's R-B development.

\section{Geographical and Characteristics of Benin Republic}

The Republic of Benin is a small country in the west part of Africa. To the north, south, east, and west, its borders on Niger and Burkina Faso, Atlantic Ocean (with a 120 square kilometers wall), Federal Republic of Nigeria, and Togo, respectively. Its territory covers an area of $114,763 \mathrm{~km}^{2}$ and characterized administratively by 12 regions from south to north with about 11 324032 inhabitants (Doing Business, 2016). From the port and commercial center of Cotonou in the south to the Niger border on the north, the distance is approximately $700 \mathrm{~km}$.

The transportation infrastructure of the country is derived of its history and geography. Benin's classified national road network hinges on four major service corridors, namely a coastal highway (Lome-Cotonou-Lagos), two north-south corridors (Cotonou-Savalou-Djougou-Porga-Burkina-Faso border and Cotonou-Parakou-Malanville-Niger border) and the transverse road (Togo border-Djougou-Nikki-Chicandou-Nigerian border) as depicted the below Figure 1.

Though Benin Republic has superior location advantage, its economic foundation is very weak [12]. The formal transport sector contributes approximately 7 percent of GDP. Agricultural structure lacks of adjustment, the development of secondary industry is restricted and the tertiary industry just starts [13-15]. All these obstruct the whole country economic development.

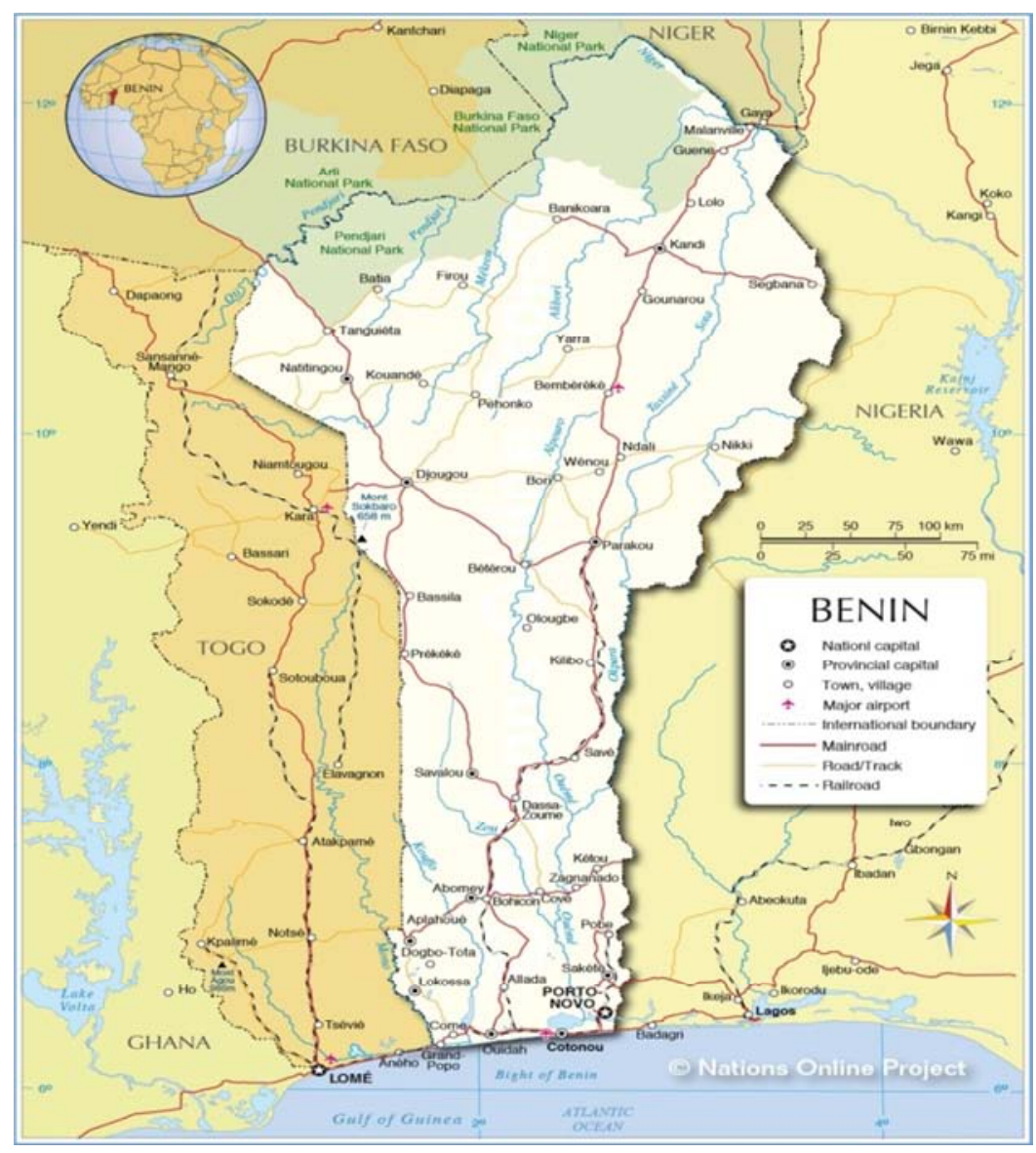

Figure 1. Road network of Benin Republic.

\subsection{Road and Bridge Development Efforts}

Over the last few years, NGB has made tremendous efforts in developing and improving the road network to enable efficient development of the country infrastructure $[1,11]$. In order to secure and preserve such valuable asset, timely and appropriate rehabilitation and maintenance interventions must take place. Further, the development of road network is 
expected to continue and both rehabilitation and maintenance activities and the design of new R-B will require reliable traffic load and construction material data.

At independence in 1960, the Beninese landscape dotted with a skeletal network of trunk roads as well as secondary and feeders roads that exhibited the characteristics which reflected the purpose of their construction. They were narrow, unpaved seasonal and winding for they were simply meant to facilitate the evacuation of agricultural produce from the interior to the ports for exports in addition to serving as links between scattered human settlements thus permitting ease of administration [3-4]. There are virtually no effective means of communication. For instance, in areas where hospitals are built, it is difficult to receive timely medical treatment because of bad road traffic condition.

Beninese's physical characteristics and the requirements of fast economic growth led (starting in the 1990s) to the establishment of a vast road network; a far-reaching structural and economic reforms with the task of transforming the national areas through the provision of basic amenities namely; education, electricity, potable water, communication, good access R-B system. What informed government decision was that good access R-B system would enhance integrated national development and growth and bring important social benefits and cohesion. Hence, NGB determination to link the different areas of the local government with a minimum 10 kilometers tarred roads.

\subsection{Roads and Bridges Development}

Benin Republic is a thickly populated, blessed with undulating topography, which ordinarily would have made it easy to navigate the entire state in a matter of hours. However, there are important deficiencies of about thousands of kilometers of earth roads which serve villages and agricultural areas. In some cases where adequate infrastructures exist, the roads are impassable to vehicles because of the severe deterioration of the road network formation, which is due either to inadequate construction or lack of maintenance or a combination of the two [4]. Even where trafficable R-B exist, they are frequently impassable during critical periods of planting and input supply and at other times can only be used if high vehicle operating costs are tolerated.

Efficient and effective R-B, and means of transport, make a crucial contribution to economic development and growth and bring important social benefits. Poorly maintained R-B constrain mobility, significantly raise vehicle operating costs, increase accident rates and their associated human and property costs, and aggravate isolation, poor health, poverty, and illiteracy in rural communities [16]. Suffice to add that rural areas in Benin Republic city house a number of resources convertible for industrial purposes. But since these villages are inaccessible, nobody would come. That is the evil of not having good rural access road networks and bridges system. It makes investors turn away from any society, however cheap the raw materials are. These and other problems associated with poor R-B in the whole country informed government determination in committing funds to the construction of R-B, rehabilitation of R-B to link all the different areas of the local government as shown in Tables $1 \& 2$ (data from our first question survey). However, the pace of progress in R-B development in the whole country varies from region to region and is insufficient to reach the 2025 Agenda targets for sustainable development.

Table 1. Construction of some important bridges (2005-2015).

\begin{tabular}{lll}
\hline S/N & Project title & Local \& National Government \\
\hline 1 & Fifadji Bridge & Local-NGB \\
2 & Godomey Interchange Bridge & NGB-China \\
3 & Overpass Houeyiho & NGB \\
4 & Kindonou Bridge & NGB \\
5 & Second Bridge & NGB \\
6 & Third Bridge & NGB \\
7 & Overpass Steinmez & NGB \\
8 & Guezin Bridge & NGB \\
9 & Tovegbamey Bridge & NGB \\
10 & Allada Bridge & NGB \\
11 & Massi Bridge & NGB \\
12 & Thalinga Bridge & NGB \\
13 & Affon Bridge & NGB \\
14 & Athieme Bridge & NGB \\
\hline
\end{tabular}

Table 2. Construction and rehabilitation of roads (2005-2015).

\begin{tabular}{|c|c|c|c|}
\hline $\mathbf{S} / \mathbf{N}$ & Project Location & No. of kilometer & Cost \\
\hline 1 & Beroubouay-kandi-malanville roads & $170.0 \mathrm{~km}$ & $56 \mathrm{~b}$ \\
\hline 2 & Parakou- beroubouay roads & $152.0 \mathrm{~km}$ & $45 \mathrm{~b}$ \\
\hline 3 & Parakou-Djogou roads & $137.0 \mathrm{~km}$ & $68 \mathrm{~b}$ \\
\hline 4 & Djougou-Ndali roads & $125.0 \mathrm{~km}$ & - \\
\hline 5 & Akassato -bohicon roads & $102.0 \mathrm{~km}$ & $50 \mathrm{~b}$ \\
\hline 6 & sortie parakou-bembereke roads & $100.0 \mathrm{~km}$ & $23 b 224468921$ \\
\hline 7 & Godomey-hillacodji roads & $98 \mathrm{~km}$ & $83 b$ \\
\hline 8 & Akpro-misserete roads; dangbo-AdjohounBonou-Ouinhi-kpedekpo roads & $90.0 \mathrm{~km}$ & $21 \mathrm{~b} 336387186$ \\
\hline 9 & N'dali-nikki-chicandou roads & $77.0 \mathrm{~km}$ & $23 \mathrm{~b}$ \\
\hline 10 & Kandi- Banikoararoads & $68 \mathrm{~km}$ & - \\
\hline 11 & Come Zoungbonou roads & $43.0 \mathrm{~km}$ & $10 \mathrm{~b}$ \\
\hline 12 & Djougou-Ouake roads & $37.0 \mathrm{~km}$ & $11 \mathrm{~b}$ \\
\hline 13 & Pahou Tori Allada roads & $37.0 \mathrm{~km}$ & $13 b$ \\
\hline 14 & Pahu-Ouidah roads & $18.75 \mathrm{~km}$ & $29 b$ \\
\hline 15 & Godomey-Pahou roads & $16.5 \mathrm{~km}$ & $23 b$ \\
\hline 16 & Godomey-Calavi roads & $10.5 \mathrm{~km}$ & $26 b$ \\
\hline 17 & Aeroport-Place souvenir Street & $5.7 \mathrm{~km}$ & $11 \mathrm{~b}$ \\
\hline
\end{tabular}




\begin{tabular}{llll}
\hline S/N & Project Location & No. of kilometer & Cost \\
\hline 18 & Ouando-Hounsa roads & $4.61 \mathrm{~km}$ & $12 \mathrm{~b}$ \\
19 & Calavi-Akassato roads & $4.0 \mathrm{~km}$ & $6 \mathrm{~b} 3$ \\
\hline
\end{tabular}

Source: Authors' Survey, 2015

\section{Research Results Analysis}

In this section, a thorough analysis on survey results of the above requirement and corresponding satisfactory R-B measure have been conducted by the authors.

Characteristics of $R-B$

A close look reveals that, the road transport system is by far the most widely used mode of transport in the country. Of all commodity movements to and from the sea-ports, at least two-third are now handled by road transport while up to $93 \%$ of all other internal movements of goods and people take place by roads [1, 3-4]. Transport can contribute to the economy directly through addition to capital stock via increases in transport infrastructure capital. Transport provides the arteries through which the economic life of the people, information and raw materials as well as finished products can be moved from one place to the other therefore helping to build and maintain the society thereby leading to economic growth in Benin. However, road network condition varies from one region to another and its infrastructure insufficiency persists. The general level of infrastructure development in Benin is still low. Average per capita infrastructure is comparatively low due to population growth and the widespread underdevelopment of the infrastructure especially the road transport system. This agrees with similar funding by the group World Bank. Indeed, in 2013, the group had arrived at the end of his analysis of road transport mobility within Benin, in the context of providing a framework to help the government analyze R-B sector issues and finalize the update of it strategy.

The main conclusions are below: The main road network ("Classified road network") amounts about 6,076 km (Decree No. 2001-092 of 20/02/2001). Out of a total of 15,700 km, the new road classification carried out in 2001 defined 2,178 $\mathrm{km}$ as inter-state roads (Routes Nationales Inter-Etat-RNIE), and $3,898 \mathrm{~km}$ as national roads (Routes Nationales-RN), [17]. Over than 30 percent of the classified road network is currently paved and represents almost one third of the total of classified road network in good condition. This percentage has not changed yet, because the surveys we conducted confirm these results. The data in the Figure 2 are derived from results of the survey questions 2 of associated with the below results.

The realization of road infrastructure is a priority for the government, which seeks to open up many localities to facilitate the smooth flow of goods, making access easy to market to people and enable good transportation with neighboring countries and beyond as well. However, still huge challenges remain for the national road network. Indeed, until we conducted the survey, only $30 \%$ of the classified national road network is in good condition. Approximately $25 \%$ is in poor condition and needs to be updated to relieve populations. Summing, we offer the strip chart below summarizes the quality of the classified national road network in Benin Republic.

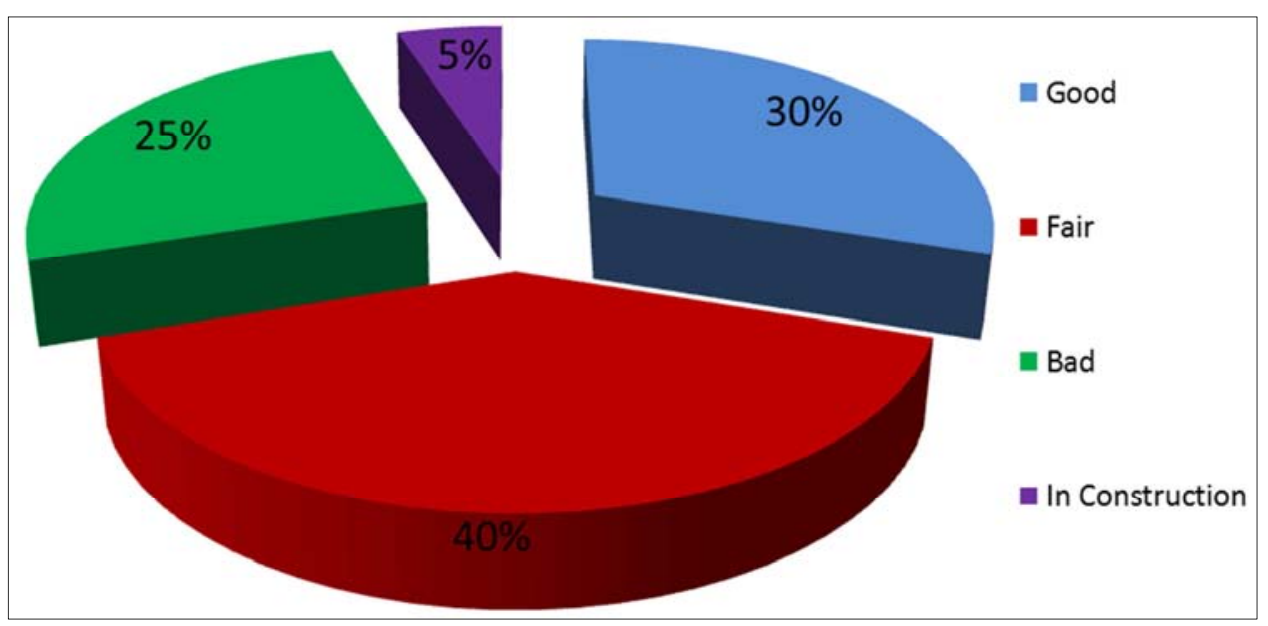

Figure 1. Distribution of classified road network quality in Benin Republic.

To get information from the commercial drivers and their level of satisfaction concerning the condition of road networks and bridges system in the different areas, we drew the Table 3 that from the answers to question 3 of our questionnaire. Among others, road surface, road condition, and reliability in all season are the indices used to assess the road quality in the areas. Table 3 shows the quality of roads in the different study areas; road quality is an attribute of road transportation system. The condition of road network in the study area varies from one region to another. Some regions enjoy good roads while some do not. For example, the Table 3 shows that $85 \%, 75 \%$ and $65 \%$ of respondents respectively in Atacora-Donga, Alibori-Borgou and MonoCouffo indicated that there are roads with good surface 
condition while in Zou-Collines, Oueme-Plateau and Atlantique-Littoral responses to good surface condition was low, $30 \%, 35 \%$ and $40 \%$ respectively according to the field survey results. In addition to these statistical results, these figures reflect a social reality in Benin Republic. This shows that there are disparities in the levels of development, hence, there is no uniform R-B development in these areas. This has a significant effect on the overall development in the whole country. Response on the reliability of roads in all season shows that the roads in the area are seasonal in nature. This is the result of a bad surface condition and poor drainage system along the roads in the concerned areas. That is why R-B infrastructure projects must be undertaken during the dry season. The field survey shows that some road surfaces which were constructed were washed away by rain only a few months after construction. Further, some graded roads became water locked and impassable forcing the people using such road to look for alternative routes.

The field experience results are compiled in before the following pie chart to make it more appealing given the Table 3.

Table 3. Quality of roads in different regions area, Benin Republic.

\begin{tabular}{|c|c|c|c|c|c|}
\hline Regions & Road Length(km) & Variables & Attributes & Number of response & Percentage $\%$ \\
\hline \multirow{4}{*}{ Zou-Collines } & \multirow{4}{*}{1312} & Surface & Good & 30 & 30.0 \\
\hline & & Condition & Bad & 70 & 70.0 \\
\hline & & \multirow{2}{*}{ Reliability in raining season } & Reliable & 72 & 72.0 \\
\hline & & & Not Reliable & 28 & 28.0 \\
\hline \multirow{3}{*}{ Oueme-Plateau } & \multirow{3}{*}{427} & Surface & Good & 35 & 35.0 \\
\hline & & Condition & $\mathrm{Bad}$ & 65 & 65.0 \\
\hline & & Reliability in raining season & Reliable & 40 & 40.0 \\
\hline \multirow{4}{*}{ Mono-Couffo } & \multirow{4}{*}{470} & Surface & Good & 65 & 65.0 \\
\hline & & Condition & Bad & 35 & 35.0 \\
\hline & & \multirow{2}{*}{ Reliability in raining season } & Reliable & 55 & 55.0 \\
\hline & & & Not Reliable & 45 & 45.0 \\
\hline \multirow{3}{*}{ Atlantique-Littoral } & \multirow{3}{*}{529} & Surface & Good & 45 & 45.0 \\
\hline & & Condition & $\mathrm{Bad}$ & 55 & 55.0 \\
\hline & & Reliability in raining season & Reliable & 10 & 10.0 \\
\hline \multirow{4}{*}{ Atacora-Donga } & \multirow{4}{*}{1550} & Surface & Good & 85 & 85.0 \\
\hline & & Condition & $\mathrm{Bad}$ & 15 & 15.0 \\
\hline & & Reliahility in rining season & Reliable & 90 & 90.0 \\
\hline & & 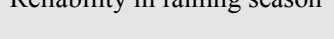 & Not Reliable & 10 & 10.0 \\
\hline \multirow{4}{*}{ Alibori-Borgou } & \multirow{4}{*}{1656} & Surface & Good & 75 & 75.0 \\
\hline & & Condition & $\mathrm{Bad}$ & 25 & 25.0 \\
\hline & & \multirow{2}{*}{ Reliability in raining season } & Reliable & 80 & 80.0 \\
\hline & & & Not Reliable & 20 & 20.0 \\
\hline
\end{tabular}

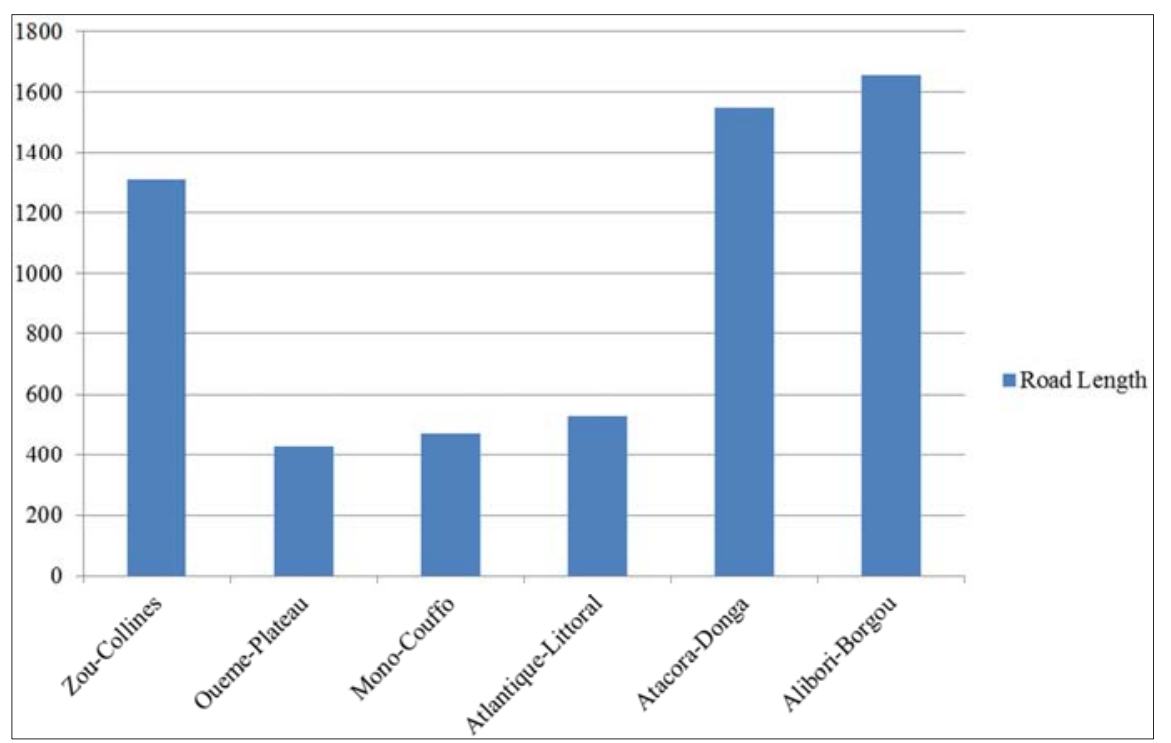

Figure 2. Regional distribution of classified road network length.

This graph clearly display the highest inequality gap in road network development. There are disparities in the levels of road development in Benin Republic and the proportion related. For instance, Figure 3 shows that Alibori-
Borgou(27.86\%) road network was high, followed by Atacora-Donga(26.08\%) and Zou-Collines(22.07\%) while Atlantique-Littoral, Mono-Couffo and Oueme-Plateau road network was low, $8.90 \%, 7.91 \%$ and $7.18 \%$ respectively. 
This represents only the classified road network coverage. Hence, there is no uniform road infrastructure development in these areas. This has a significant effect on the overall development in the whole country. This therefore shows that the state of national roads network in the country still remains predominantly underdeveloped.

\section{Provisions and Construction of R-B Infrastructure}

The past efforts and experiences have revealed that there are some constraints to develop basic road infrastructure. Valuable data gathered from the head of works revealed that rehabilitation and maintenance of existing R-B and construction of new ones have been difficult due to frequent change in both national and local government chairmen in the past. As gathered, a change in the national or local government chairmanship also brings about change in the R-B infrastructure priority list of the new national or local government chairmen which affects development. Funding has always remained as a key issue which has made the local government incapable to carry out major R-B projects. Besides, the construction of R-B is monopolized by the government. The roles of foreign investors, private sector, and the society in general in infrastructure development is limited to certain fields, geographical region, and investment scales unlike in other sectors that have been the target of economic reforms. As a result, capital can't be mobilized through various channels, and resources can't be optimized.

\section{Conclusions and Recommendations}

From this study, it has clearly come out that inequitable distribution of R-B infrastructure in the study area has resulted in the disparities in development that are primarily influenced by transportation. This situation is still redeemable. Managing, therefore, the construction of $\mathrm{R}-\mathrm{B}$ becomes imperative in turning around the study area. The level of development in some areas is low and this is as a result of the poor road condition among other contributing chief factors. Therefore, there the is need for adequate provision of national transportation and other infrastructural facilities to improve the level of development in these areas. A need will also exist for urban interchanges and pedestrian bridges, due to the continuous increase of traffic volume, not only in Cotonou area but also in the other major cities.

The major challenge for all R-B will be systematic maintenance and improvement in order to meet today's increased traffic loads. Considering Benin population and size, it is not possible for NGB only to meet substantial parts of the needs of every region. To be able to do this and more effectively, there is need to encourage public participation in provision of basic facilities through various community selfhelp development programs. Governmental monopoly in infrastructure development calls for a reassessment at the very least. Similarly, Citizens' empowerment towards the development of their community to reduce the level of dependence on NGB was also recommended.

Various government policies on national development asset in the past have died with the government that initiated it. There is need for successive government to uphold policies formulated by their predecessors to ensure that the aim is achieved rather than formulating new policies without achieving its aim. These issues need to be addressed well as the country moves towards 'construction of New Benin' known as "Benin 2025 Alafia" that sets out long term goals in the National Studies. This is an opportunity that should not be swept under carpet.

The secondary data collection from government department and organization was limited and unclassified due to poor resource. The extensive primary data collection was also not possible due to requirement of large human and other resources along with permission from government organizations. Despite the limitations that have been revealed, this research contributed to:

The brief synopsis of Benin Republic, which highlights the historic, geographic, and socio-economic contexts of the country; the presentation of R-B infrastructure development agreeable priorities issues with it provision. Further, road network distribution and the roads quality are elucidated. Finally, some recommendations have been made and proposals formulated in aim to respond efficiently to the R-B infrastructure problem within Benin and avoid the future ones. It will also help to cater to the increasing future transportation demands and achieving sustainable development of the country.

Above all, there should be political will on the part of the successive NGB to see R-B infrastructure as a propelling force for national transformation.

\section{Acknowledgement}

The authors are grateful for the financial supports from the National Natural Science Foundation of China (51378430) and the Department of Bridge Engineering, South West Jiaotong University(SWJTU). Other significant contributions of the study were made by Prof. Zhang Xun.

\section{References}

[1] Dossa Didier Boko-haya, Yadong Li, Changrong Yao, Bin Qiang"Investigation on Bridges Connection to Network Carrefour in Existing Roads in Africa Big Cities: The Case of Cotonou in Benin Republic" Vol. 6-Issue 4 (April-2016), International Journal of Engineering Research and Applications (IJERA), ISSN: 2248-9622, www.ijera.com

[2] Strategy Paper reduction of poverty in Benin PRSP. (2002), pp. 29.

[3] Carolina Dominguez-Torres and Vivien F. Benin's Infrastructure: A Continental Perspective. (2011) pp. 4-13. 
[4] D. D. Boko-haya, Y. D. Li, C. R. Yao, Y. Gu, B. Qiang, Q. Q. Xiang, "Development of Conceptual Model for Overcoming the Challenges of Road and Bridge Infrastructure Development: Towards Innovative Solutions in Benin Republic", International Journal of Engineering Research in Africa, Vol. 26, pp. 161-175, 2016

[5] Strategy Paper reduction of poverty in Benin (PRSP 20112015) Year (2011), pp. 29.

[6] AICD (Africa Infrastructure Country Diagnostic). ECOWAS's Infrastructure: A Regional Perspective. Africa Region, World Bank, Washington, DC, 2010.

[7] Yepes, Tito, Justin Pierce, and Vivien Foster. Making Sense of Africa's Infrastructure Endowment: A Benchmarking Approach. Policy Research Working Paper 4912, World Bank, Washington, DC. 2009.

[8] World Bank Group; International Finance Corporation. Doing Business 2016 Economy Profile: Benin Washington, DC, 2016.

[9] Declaration of population policy (DEPOLIPO/1996, pp.8-11).

[10] Foster, V., and Cecilia B. Garmendia, C. Africa's
Infrastructure: A Time for Transformation. Paris and Washington, DC: AgenceFrançaise de Développement and World Bank, 2010.

[11] Stratégie Sectorielle des Transports, Benin. (2014-2018), pp. 26.

[12] Human Development Report (PDF). United Nations Development Program. Retrieved 14 December, 2015.

[13] Information on http://ec.europa.eu/europeaid/countries/benin_en. Last access: Tuesday 1 November, 2016.

[14] Information on http://www.state.gov/r/pa/ei/bgn/6761.htm. Last access: Sunday 15 November, 2016.

[15] World Bank, Benin Country Brief (2016). Last access: Friday 12 November, 2016.

[16] Cesar Queiroz and SurhidGautam. Western Africa Department and Infrastructure and Urban development Department. The World Bank WPS 921(1992), pp. 3-12.

[17] Carolina Dominguez-Torres and Vivien F., Benin's Infrastructure: A Continental Perspective, 2011, pp. 5-8. 